\title{
Potencial de biocontrole das leveduras em pós-colheita de citros pela produção da enzima $\beta$-1,3-glucanase e atividade killer: uma revisão
}

\author{
Pablo Leal Rodrigues ${ }^{1}$, Jaqueline Lima da Silva ${ }^{1}$, Josiane Pacheco de Alfaia ${ }^{1}$, \\ Joel Correa de Souza ${ }^{1} \&$ Luana Pereira de Macedo ${ }^{1}$
}

\section{RESUMO}

Brasil é o maior país produtor e exportador de frutos cítricos do mundo, apesar disso, sua produção é afetada por doenças fúngicas durante a pós-colheita, esses patógenos causam danos quantitativos, qualitativos, econômicos e podem causar danos à saúde humana. Dentre essas doenças, destacam-se os patógenos do gênero Penicillium spp. que são considerados uma ameaça a citricultura em todo o mundo. A aplicação de fungicidas ainda é o método mais utilizado para o seu controle, porém, o uso desses produtos pode ocasionar uma série de problemas tais como selecionar linhagens resistentes do fitopatógeno pelo seu uso intensivo e também pelos riscos saúde humana e do meio ambiente, o que levou os pesquisadores a elaborarem estratégias alternativas e métodos inovadores como o uso de micro-organismos como agentes de controle biológico, a exemplo as leveduras, devido ao seu grande potencial biológico, pois algumas espécies de levedura tem a capacidade de produção de enzimas hidrolíticas como a $\beta$-1,3-glucanase, além da produção de toxinas killer e da alta capacidade colonização de feridas, que representam importantes mecanismos de ação empregados no biocontrole de fitopatógenos. Neste sentido, o presente trabalho teve por objetivo fazer uma breve revisão sobre a eficiência da $\beta$-1,3-glucanase e atividade killer produzida por leveduras no controle biológico do bolor verde em pós-colheita de citros.

Termos de indexação: Citrus, controle biológico, leveduras, Penicillium.

\section{Biocontrol potential of yeasts in citrus postharvest by production of $\beta$-1,3-glucanase enzyme and killer activity: a review}

\section{SUMMARY}

Brazil is the largest producer and exporter of citrus fruits in the world, despite that, its production is affected by fungal diseases during post-harvest, these pathogens cause quantitative, qualitative, economic damage and can cause damage to human health. Among these diseases, pathogens of the genus Penicillium spp. that are considered a threat to citrus culture worldwide. The application of fungicides is still the most used method for its control, however, the use of these products can cause a series of problems such as selecting resistant strains of phytopathogen due to their intensive use and also due to the risks to human health and the environment, the which led researchers to devise alternative strategies and innovative methods such as the use of microorganisms as biological control

\footnotetext{
${ }^{1}$ Universidade Federal Rural da Amazônia - UFRA, Belém, PA, Brasil

Autor correspondente: Pablo Leal Rodrigues, Universidade Federal Rural da Amazônia UFRA, Travessa Monte Alegre, Bairro do Jurunas, CEP 66030370, Belém, PA, Brasil. E-mail:agronopablo@gmail.com
} 
agents, such as yeasts, due to their great biological potential, as some yeast species have the capacity to produce hydrolytic enzymes such as $\beta$-1,3-glucanase, in addition to the production of killer toxins and the high capacity for colonization of wounds, which represent important mechanisms of action used in the biocontrol of phytopathogens. In this sense, the present work aimed to make a brief review on the efficiency of $\beta$-1,3-glucanase and killer activity produced by yeasts in the biological control of green mold in citrus postharvest.

Index terms: Citrus, biological control, yeast, Penicillium.

\section{INTRODUÇÃO}

As frutas cítricas estão entre as mais cultivadas em todo o mundo e sua produção está aumentando a cada ano devido à crescente demanda dos consumidores, o que gera milhões de empregos em mais de 137 países ao redor do mundo, nos processos de colheita, manuseio, transporte, marketing e entrega da produção proveniente das indústrias citrícolas (Sharma et al., 2017; Martín et al., 2018).

Dentre os frutos citros, as laranjas são as mais produzidas, obtendo-se uma produção mundial de aproximadamente 71 milhões de toneladas, onde o Brasilé o maior país produtor e responde por $76 \%$ de participação no comércio mundial de suco de laranja, sendo também o maior fornecedor, o que reflete o fato de três quartos do suco de laranja consumida no planeta ser produzido no país. A safra de laranja 2019/20 do cinturão citrícola de nacional é reestimada em 384,87 milhões de caixas, de acordo com atualização publicada em 11 de fevereiro pelo Fundecitrus. $\mathrm{O}$ valor é apenas $0,11 \%$ menor do que a reestimativa anterior, de dezembro de 2019 , e $1,03 \%$ inferior à primeira estimativa, de maio de 2019. (FAO, 2016; IBGE, 2017; USDA, 2018; FUNDECITRUS, 2019).

No país, há uma predominância na produção da região Sudeste sobre as demais regiões produtoras, o estado de São Paulo é o maior produtor, tanto regional quanto nacional, devido a sua grande concentração de pomares de laranjeiras doces, com produção de 10.465.335 toneladas, em uma área de 471.200 hectares, favorecidos pelas condições edafoclimáticas propícias ao desenvolvimento da atividade, tais como o clima subtropical mesotérmico, úmido, com temperatura média de $21^{\circ} \mathrm{C}$, e estiagem branda no inverno, radiação solar global bastante elevada, além da proximidade com o mercado externo (Viana \& Amorim, 2008; Belo, 2017; Carvalho, 2017).

Na região Nordeste os estados da Bahia e Sergipe apresentam maior destaque na produção de citros, de acordo com os dados do IBGE (2015), tendo a região do Agreste de Pernambuco um grande potencial de expansão da atividade, devido as suas condições climáticas adequadas para a produção de frutos como; clima predominantemente Mesotérmico Tropical de Altitude (cs’a), com estações de verão e inverno bem definidas de acordo com a classificação climática de Köppen, a região apresenta ainda altitudes superiores a $800 \mathrm{~m}$ e temperaturas que variam de 20 a $24^{\circ} \mathrm{C}$ (Passos et al., 2005; Medeiros et al., 2013)

Apesar da grande produção citrícola do país, problemas com doenças fúngicas em pós-colheita comprometem o desenvolvimento dessa atividade; o manuseio e processamento inadequado dentro do packing house, causam feridas superficiais nos frutos que podem ser infectadas por patógenos durante vários dias, comprometendo toda a produção (Moretto et al., 2014).

Doenças como a podridão marrom, mancha septoria, antracnose, bolor verde / azul e podridão azeda causadas por, respectivamente, Phytophthora spp. Septoria citri.,Colletotrichum gloeosporioides., Penicillium spp. e Geotrichum citri-aurantii., são exemplos que emergem como resultado de lesões causadas pelo manuseio inadequado no campo ou nas fases subsequentes após a colheita (Simas et al., 2017).

Entre os principais causadores de danos na pós-colheita de citros, destacam se as doenças causadas por Penicillium digitatum, causador do bolor verde, este fungo é responsável por grandes perdas na produção, pois pode provocar podridão mole no fruto, recoberta por micélio branco com um grande número de esporos, os quais the dão uma coloração verde posteriormente. E pelo fungo Penicillium italicum, causador do bolor azul, sua incidência é menor que a do bolor verde, apesar do ciclo da doença e os sintomas serem similares ao bolor verde apesar de crescer em um ritmo menor em baixas temperaturas (Fischer et al., 2007, 2008; Ferraz et al., 2018).

A aplicação de fungicidas químicos sintéticos é o método mais comum para limitar a decomposição pós-colheita e infecções durante o armazenamento, porém, os produtos químicos utilizados são tóxicos e poluentes, impactam o meio ambiente e comprometem a saúde dos produtores agrícolas e consumidores, portanto é imprescindível desenvolver métodos seguros e estratégias alternativas eficazes para controlar a doença pós-colheita, bem como aumentar a vida útil das frutas (Dudley et al., 2017; Jatoi et al., 2017; Sun et al., 2017). 
Atualmente, estudos apontam que as leveduras possuem várias características que as tornam potenciais candidatas como agentes de biocontrole, uma delas é a capacidade de produzir a enzima $\beta$-1,3-glucanase, que atua diretamente na parede celular dos fungos causadores de doenças. O produto comercial Aspire ${ }^{\circledR}$, é utilizado para o controle biológico de podridões na pós-colheita de citros e de outras frutas e tem como base a levedura Candida oleophila, devido à produção da enzima $\beta$-glucanase (Droby et al., 1998; Bauermeister et al., 2010; O'Kennedy et al., 2011; Vos et al., 2014; Montiel et al., 2018).

Diante do exposto, o presente trabalho teve por objetivo fazer uma breve revisão sobre a eficiência da $\beta$-1,3-glucanase e atividade killer produzidos por leveduras no controle biológico do bolor verde em pós-colheita de citros.

\section{ORIGEM E ASPECTOS BOTÂNICOS DOS FRUTOS CÍTRICOS}

Os frutos cítricos têm seu provável centro de origem nas regiões úmidas tropicais e subtropicais do continente Asiático, mais precisamente Indochina e Sul da China, sendo sua principal origem o leste da Índia, existem livros escritos durante a dinastia Chon, de 1027 a 256 a.C., que já mencionavam o cultivo de certas plantas, como a espécie cítrica Poncirus trifoliata (L.) Raf., nativa do centro e do Norte daquele país, e muito usada como porta-enxerto. Após adentrar no continente Africano e posteriormente no continente Americano foram introduzidos no Brasil, pelos portugueses, no começo do século XVI, talvez a partir de 1530, quando teve início a colonização (Donadio et al., 2005; Oliveira et al., 2012).

Quanto a sua classificação botânica, os frutos cítricos são classificados como Espermatófitos, pertence à subdivisão das Angiospermas, a classe das Eudicotiledôneas, e família das Rutáceas, apresentam 13 gêneros, sendo o gênero Citrus o mais conhecido e também um dos mais estudados, ele abrange as espécies Citrus medica L. (cidra), Citrus limon (L.) Burm. f. (limão verdadeiro), Citrus sinensis (L.) Osbeck (laranja doce), Citrus aurantium L. (laranja azeda), Citrus aurantiifolia (Christm.) Swingle (limas), Citrus maxima (Burm.) Merr. (toranjas), Citrus paradisi Macfad. (pomelo), Citrus reticulata Blanco (tangerinas) dentre outros representantes (Gomes, 1972; Amaral, 1982; Koller, 1994, GRIN, 2013).

O gênero Citrus é representado por plantas de porte médio, sendo arbóreo ou arbustivo, com flores brancas e aroma característico, apresenta frutos tipo baga (hesperídio), contendo vesículas preenchidas por líquido, que constitui o suco de grande interesse comercial. Em sua composição os frutos são compostos por epicarpo (casca), mesocarpo (parte de aspecto esponjoso e de coloração branca), também chamada de albedo, endocarpo (parte comestível do fruto composta pelos gomos), e as sementes, que auxiliam em sua disseminação (Lorenzi et al. 2006; Oliveira Junior, 2015).

As características físicas e químicas dos frutos variam no decorrer do período de maturação, e essa variação depende, entre outros fatores, das condições meteorológicas durante a formação e a maturação dos frutos, combinação porta-enxerto/variedade copa, a idade da planta, os estresses hídricos e de temperatura, a localização do fruto na árvore, a radiação solar, as práticas de manejo, principalmente a irrigação, a nutrição e o espaçamento entre as plantas (Reuther, 1973; Volpe et al., 2002).

\section{A CITRICULTURA NO BRASIL E NA REGIÃO NORDESTE}

A citricultura é uma atividade que tem forte contribuição para desenvolvimento do Brasil desde 1962, com o início das exportações, porém só passou a ter maior relevância, na década de 80 do século XIX, no Estado do Rio de Janeiro, através da exportação da laranja in natura. Essa forte impulsão esteve relacionada a fatores climáticos como fortes geadas que afetaram a Flórida nos anos de 1977, 1981, 1982, 1983, 1985 e 1989, o que causou perdas na produção americana de laranja, firmando as exportações de suco brasileiro. A citricultura brasileira se destaca atualmente por ter a maior produção mundial sendo responsável por mais de $60 \%$ das exportações, tendo como principal produto de exportação o suco de laranja concentrado (Borges \& Costa, 2006; Neves et al., 2010; Turra et al., 2014; MAPA, 2016; Turra \& Santos, 2016; Fonseca, 2017).

O Brasil responde por mais da metade do suco produzido em todo o mundo, considerando a média de produção a contar das safras de 2012 em diante, citadas no levantamento mundial feito pelo Departamento da Agricultura dos Estados Unidos (USDA) de acordo com Neves \& Trombin (2017). O Instituto Brasileiro de Geografia e Estatística (IBGE) publicou que a safra de 2015/2016 apresentou uma produção de laranja estimada em 16,7 milhões de toneladas, ocupando uma área de 664,4 mil hectares. Após uma produção elevada em 2017/18, as primeiras impressões são de que a safra $2018 / 19$ pode 
ser novamente de oferta mais restrita no estado de São Paulo e no Triângulo Mineiro, segundo pesquisa feita pelo Centro de Estudos Avançados em Economia Aplicada (CEPEA) da ESALQ/USP (CEPEA, 2018).

O restante da produção está concentrado nos estados da Bahia, de Minas Gerais, Sergipe, Paraná e Rio Grande do Sul. Vale observar ainda que o volume a ser produzido pelo Brasil poderá ser maior, em virtude das condições climáticas favoráveis como temperaturas amenas e disponibilidade hídrica observada no final de 2015 e início de 2016, nas regiões produtoras (CONAB, 2017).

A região Nordeste é a segunda maior região produtora de citros do Brasil, apresentando 1,6 milhões de toneladas na sua produção de acordo com a região do médio São Francisco, mais precisamente o semiárido nordestino, onde se encontra o polo irrigado de Petrolina (PE) /Juazeiro (BA), também é vista como uma fronteira para a ampliação da produção de citros no país e para o processamento de suco para o mercado externo. Porém no manejo, os fungos são tidos como um dos maiores problemas relacionados a perdas (Pereira, 2009; Piati et al. 2013; IBGE, 2013).

\section{DOENÇAS E PERDAS EM PÓS-COLHEITA DE FRUTOS CÍTRICOS}

As doenças pós-colheita, especialmente aquelas causadas por patógenos fúngicos, proporcionam perdas econômicas significativas, além disso, alguns fungos também produzem micotoxinas que representam um risco para a saúde humana, ao suprimento de alimentos no planeta e a economia (Liu et al., 2018).

Por serem bastante ácidos e presentarem condições propícias ao crescimento de patógenos os frutos cítricos são comumente atacados por fungos, esses fungos se aproveitam de um ambiente rico em nutrientes, umidade e boa temperatura para se desenvolverem, os patógenos podem infectar o hospedeiro através de ferimentos superficiais ocorridos dentro do packing house durante a colheita, transporte e manipulação dos frutos sendo que as perdas em pós-colheita causadas por patógenos fúngicos no mundo têm alcançado até $90 \%$ da produção (Bautista-Baños et al., 2013; Talibi et al., 2014; Valenzuela et al., 2015; Karim et al., 2015; Liu et al., 2018).

Em levantamento da incidência de doenças pós-colheita em frutas comercializadas na Central de Abastecimento de Recife em Pernambuco, foi detectado que 21,9\% dos frutos analisados apresentavam doenças fúngicas, confirmando a importância das doenças pós-colheita em frutos na economia, a pesquisa ressalta ainda, que medidas de controle mais efetivas durante as fases de produção e pós-colheita, como práticas de sanitização e métodos que induzam resistência ao patógeno, são importantes tendo em vista a redução dessas perdas (Dantas et al., 2003).

Quando relacionamos a redução das perdas em pós-colheita e seus impactos na economia brasileira, observamos que a preços de 2012, esta redução implicaria em aumento de R \$ 9,8 bilhões no valor da produção agrícola do país, outro reflexo disso é o aumento na demanda por serviços de processamento, transporte e comércio o que poderia gerar mais de 300 mil empregos diretos e indiretos (Costa et al., 2015).

No manejo fitossanitário em pós-colheita de citros, os fungos estão entre as doenças que mais prejudicam ampliação da oferta de frutos, o bolor verde, bolor azul, bolor cinzento, causados por, Penicillium digitatum, Penicillium italicum, Botrytis cinerea respectivamente, são relatados como sendo as doenças pós-colheita de maior importância mundial na citricultura representando perdas consideráveis na produção (Eckert \& Brown, 1986; Eckert, 1993; Tripathi et al., 2008; Solaimani et al., 2009; Gatto et al., 2011; Talibi et al., 2011).

\section{Bolor verde em pós-colheita de frutos cítricos}

O fungo Penicillium digitatum, também conhecido como bolor verde, pertence ao Reino: Fungi, Filo: Ascomycota, Subfilo: Pezizomycotina, Classe: Eurotiomycetes, Subclasse: Eurotiomycetidae, Ordem: Eurotiales, Família: Trichocomaceae, Gênero: Penicillium (Frisvad \& Samson, 2004; Houbraken et al., 2014).

A podridão causada por Penicillium digitatum Sacc., configura-se como uma das principais ameaças em pós-colheita de citros e se não for gerenciada, pode causar até $90 \%$ de perdas de rendimento durante o armazenamento e transporte. O fungo conhecido como Penicillium expansum, também, infecta frutas como maçãs, peras, uvas, pêssegos e cereais, sendo dependente principalmente de insetos ou feridas em frutos para sua colonização, o que leva rapidamente a podridão após os esporos adentrarem os locais das feridas, causando perdas significativas na indústria de frutas (Kanetis et al., 2007; Cerioni et al., 2013; Prusky et al., 2013).

Outro representante do gênero é o Penicillium citrinum, este fungo é produtor da citrinina, uma micotoxina de nefrotoxina e também é responsável por podridões de aspécto esverdeado em pós-colheita de citros, alguns 
fungos dos gêneros Penicillium tem a capacidade de produzir outras susbstâncias como a ocratoxina A(OTA) e a patulina (compostos tóxicos); capazes de causar graves problemas de saúde humana, como a redução da atividade ou eficiência do sistema imunológico e o câncer, o que representa um aumento na demanda por estratégias de controle com ações mais específicas e menos danosas ao homem e meio ambiente (Hetherington \& Raistrick, 1931; Pitt, 1979; Liu et al., 2013; Andrade et al., 2014; Fiori et al., 2014; Simoncini et al., 2014; Núñez et al., 2015; Zhu et al., 2015; Delonge et al., 2016).

\section{CONTROLES DE DOENÇAS FÚNGICAS EM PÓS-COLHEITA DE FRUTOS CÍTRICOS}

\section{Controle químico em pós-colheita de frutos cítricos}

Em pós-colheita de citros, utilizam-se os fungicidas, que prolongam o tempo de armazenamento dos frutos e reduzem o desenvolvimento dos patógenos e a deterioração causada por eles, dentre os fungicidas mais utilizados contra patógenos em pós-colheita, estão os de contato como o ortofenilfenol e dióxido de enxofre e os fungicidas sistêmicos como o tiabendazol e o imazalil de acordo com Torres et al. (2008).

O imazalil (IMZ) é o mais confiável fungicida para uso contra fungos em citros, causado por $P$. digitatum, sendo bastante utilizado em tanques de imersão para o controle curativo da doença. Porém, é um produto que oferece sérios riscos a saúde humana, podendo desencadear problemas como disfunção endócrina, neurotoxicidade, teratogenicidade e genotoxicidade, devido ser extremamente tóxico (classe toxicológica I). O tiabendazol (TBZ) é um fungicida sistêmico, protetor e de ação curativa, que possui ação parasiticida, tem classe toxicológica III, medianamente tóxico, oferecendo riscos à saúde humana e ao meio ambiente (Erasmus et al., 2011; Njombolwana et al., 2013; Jin et al. 2016; Kellerman et al., 2016; Alves, 2017).

No controle do bolor verde, causado por $P$. digitatum o IMZ reduziu a incidência da doença em $70 \%$ e a severidade em $82,7 \%$ no $8^{\circ}$ dia após inoculação do patógeno, o tiabendazol apresentou $100 \%$ de eficiência no controle em pós-colheita de laranjas pera frente a produtos alternativos (Franco \& Bettiol, 2002; Maro, 2010). Em pesquisas conduzidas por Fischer et al. (2013), frutos cítricos tratados com IMZ apresentaram menor incidência $(5,4 \%)$ de doenças pós-colheita, sendo que o fungicida TBZ também apresentou resultados favoráveis quanto a frequência relativa de isolados de $P$. digitatum resistentes ao fungicida.

No Brasil, até 2016, haviam três fungicidas registrados para uso em pós-colheita de frutas: IMZ, TBZ e Procloraz, porém, a Agência Nacional de Vigilancia Sanitária (ANVISA) devido à reavaliação toxicológica dos produtos fitossanitários utilizados no país, proibiu o uso do procloraz, tendo em vista o produto não atender mais às regras e exigências de segurança do órgão (Brasil, 2016; Alves, 2017).

Os impactos dos produtos químicos sobre a biodiversidade são feitos tanto de forma direta, pela sua ação contra um determinado patógeno, quanto indireta, atingindo os micro-organismos benéficos presentes no ecossistema, fato este que é geralmente negligenciado e as atuais estratégias de conservação dão pouca atenção a essas questões, apesar de seus efeitos prejudiciais a curto e longo prazo (Heneberg et al., 2018).

O relatório "Você não quer mais respirar veneno" publicado recentemente pela organização internacional dos direitos humanos Human Rights Watch, documentou casos de intoxicação aguda decorrentes da deriva de agrotóxicos em sete localidades, incluindo comunidades rurais, comunidades indígenas e quilombolas e escolas rurais, nas cinco regiões do Brasil, mostrando que há indícios de que os dados do governo subestimam a prevalência de intoxicações por agrotóxicos no país e o sistema nacional de monitoramento de resíduos de agrotóxicos apresenta falhas, o que compromete a saúde do homem e do meio ambiente (Human Rights Watch, 2018).

Na Europa, organizações como a GLOBALG.A.P., criada pelo mercado varejista em 1997, impõem regras que ajudam os produtores a cumprir com os critérios de segurança alimentar aceito em toda a Europa tais como: métodos de produção sustentáveis, bem-estar social e ambiental, de acordo com normas rígidas quanto aos níveis de resíduos de fungicidas utilizados, onde toda a cadeia de produção é inspecionada e certificada, sendo este, um dos principais programas de garantia agrícola do mundo (GLOBALGA.P., 2018).

Essas discussões sobre um controle mais seguro de doenças pós-colheita, em frutas e vegetais, impulsionou os pesquisadores a desenvolverem agentes antifúngicos novos e mais seguros a saúde humana e do meio ambiente. Nesse sentido, o uso de agentes de controle biológico (ACBs) ou compostos naturais, quando aplicados pouco antes ou logo após a colheita, tem se mostado um método relativamente bem sucedido (Calvo-Garrido et al., 2014; Yang et al., 2016). 


\section{Controle biológico em pós-colheita de frutos cítricos}

Atualmente a busca por uma produção agrícola sustentável esbarra em vários obstáculos, um deles é resistência por parte de agricultores que são moldados por um sistema que diz não ser possível o controle de pragas e doenças na agricultura sem a utilização de produtos químicos sintéticos. Nesse contexto, os ACBs geralmente diminuem o potencial negativo dos patógenos, seja diretamente por meio de suas atividades antagônicas ou indiretamente, através de seus efeitos modificadores no tipo de fisiologia da planta de nutrientes e patógenos envolvidos (Rocha \& Cassino, 2017; Ghorbanpour et al., 2018).

De acordo com Baker \& Cook (1974) o controle biológico é a redução da quantidade de inoculo ou da atividade de produção da doença pelo patógeno realizado por um ou mais organismos. O controle biológico também pode ser definido como a regulação de uma espécie dentro de certos limites, por um período de tempo, por qualquer combinação de fatores naturais bióticos ou abióticos, sendo que este controle pode ser direto quando os antagonistas são aplicados vivos nas espécies hospedeiras, ou indiretos, através da aplicação de outras moléculas bioativas (Diehl et al., 2012; Praneetvatakul et al., 2013; Carvalho et al., 2015).

As principais características de um agente de biocontrole ideal foram definidas por Wilson \& Wisniewski (1989) e estão relacionadas à biossegurança, atividade em uma variedade de ambientes e contra uma variedade de patogênos além da facilidade de gerenciamento e seu uso. Diversas pesquisas vêm avaliando produtos alternativos que reduzem os problemas fitossanitários, esses problemas inclinaram o campo da pesquisa para estratégias de controle alternativas de doenças, como agentes de controle biológico, tendo em vista os diversos problemas ambientais e a saúde humana relacionada aos fungicidas sintéticos (Lamovšek et al., 2013; Broetto et al., 2014).

Houve um grande impulso no desenvolvimento de ACBs para o controle de doenças fúngicas e pragas nas últimas décadas, conduzida predominantemente pela retirada de uma gama de grupos de compostos estruturais químicos de proteção de culturas pela União Europeia. Assim, o setor agroquímico reorientou as suas prioridades no controle de doenças para incluir o uso de ACBs em pesquisa e programas de controle de doenças e pragas, tanto pré quanto em pós-colheita (Medina et al., 2017).

$\mathrm{O}$ uso de compostos bioativos de origem natural parece ser um dos métodos mais promissores para o controle em pós-colheita de citros, um reflexo disso é que o mercado mundial e a indústria de produtos de controle biológico têm crescido em um ritmo cinco vezes maior que a de defensivos químicos. Essas abordagens ecologicamente sustentáveis, como o uso de fungos benéficos, ganharam atenção significativa em todo o mundo devido às suas propriedades antagônicas notáveis contra patógenos de plantas em abundantes aplicações bem sucedidas, que mostraram a alta eficácia de micro-organismos tanto no controle de patógenos fúngicos em alimentos quanto na severidade de doenças em pós-colheita de frutos (ABCBIO, 2016; Terao et al., 2017; Yang et al., 2017; Ghorbanpour et al., 2018; Montiel et al., 2018).

A exemplo disso, a levedura Debaryomyces hansenii demonstrou potencial como agente de controle biológico de invasores fúngicos em vários produtos alimentares, prevendo seu uso como componente do manejo integrado de patógenos em frutas, carnes, laticínios e grãos de cereais, podendo assim, ser uma das próximas tendências da biotecnologia no campo (Córdova et al., 2018).

A levedura Hanseniaspora uvarum Y 3, foi relatada como um potencial agente de controle biológico contra o mofo cinzento em pós-colheita de uvas e também inibiu significativamente o bolor verde das laranjas. As leveduras Aureobasidium pullulans, isoladas das folhas e frutos de Byrsonima crassifolia e Eugenia dysenterica mostraram-se promissoras como ACBs do bolor verde dos citros em ensaios in vitro e in sito, sugerindo que mais estudos são necessários para incentivar as iniciativas para descobrir medidas ecologicamente saudáveis para o controle da doença na pós-colheita (Liu et al., 2010; Qin et al., 2015; Sperandio et al., 2015; Li et al., 2016).

Em estudo sobre os mecanismos de ação de isolados de leveduras envolvidos no biocontrole de $P$. digitatum em citros, Ferraz et al. (2018) mostraram que isolados de Candida stellimalicola, apresentaram produção da enzima hidrolítica quitinase na presença da parede do fungo, a atividade Killer e a inibição da germinação de conídios do fitopatógeno esses mecanismos foram indicados como os principais responsáveis para o biocontrole do bolor verde em pós-colheita de citros.Em pesquisas conduzidas por Estrada et al. (2017) sobre revestimentos bioativos, foi verificado que os composto produzidos pela levedura D. hansenii demonstraram um potencial de aplicação em revestimentos bioativos a base de leveduras para previnir a infecção por $P$. italicum para avaliação da proteção pós-colheita de citros durante 13 dias, a pesquisa mostrou que a aplicação preventiva dos tratamentos foram mais eficazes ao nível de $70 \%$ que as aplicações curativas no 
controle do bolor azul, sendo esta, uma alternativa de manejo em pós-colheita de citros.

Essa correlação entre leveduras e sua atividade biocontroladora também foi verificada no trabalho apresentado por Liu et al. (2019), que avaliaram os diferentes modos de ação de três espécies de levedura contra $P$. digitatum e P. italicum em frutos cítricos, observaram que os micro-organismos apresentaram importantes mecanismos envolvidos na atividade de biocontrole, tais como a indução de resistência do hospedeiro, forte capacidade de colonização do tecido hospedeiro, parasitismo direto, alta produção enzimática responsável pela degradação da parede celular fúngicas, sendo esses, importantes mecanismos envolvidos na atividade de biocontrole.

\section{Controle biológico por leveduras em pós-colheita}

As leveduras são fungos que apresentam grande importante nas indústrias químicas, farmacêuticas, de alimentos e também na agricultura, atualmente uma alternativa ao controle de doenças em pós-colheita de frutas é através do uso de leveduras. Esses micro-organismos são classificados como unicelulares pertencentes ao reino Fungi, estão inseridas no subreino Dikarya, e filos Basidiomycota ou Ascomycota e classe dos ascomicetos, os quais se reproduzem assexuadamente por brotamento ou fissão binária (Feyder et al., 2015; França, 2016; Cunha et al., 2018).

Várias leveduras antagonistas foram eficazes como agentes de controle biológico para controlar doenças de cítrico, como Pichia membranefaciens Hansen, Pichia guilliermondii Wiskerham, Candida oleophila Montrocher, Candida farmata Meyer \& Yarrow, Candida Saito e Ota, Candida saitoana Nakase \& Suzuki, Aureobasidium pullulans (de Bary) Arnaud, Saccharomyces cerevisiae Hansen, Metschnikowia fructicola Kurtzman \& Droby, Metschnikowia pulcherrima Pittes \& Miller e Debaryomyces hansenii Lodder \& Kre-Van Rij (Fang \& Tian, 2000; Sharma et al., 2009; Sperandio et al., 2015).

A vantagem do uso de leveduras no controle de doenças de pós-colheita deve-se ao fato destes organismos serem os maiores componentes da comunidade microbiana na superfície de folhas, frutos e vegetais. O uso de espécies de leveduras representa uma estratégia promissora à luz de sua capacidade para colonizar e sobreviver na superfície da fruta por um longo período, além da sua necessidade econômica de nutrientes (Wilson et al. 1993; Lahlali et al., 2011; Spararo \& Droby, 2016).

Esses micro-organismos vêm sendo utilizados como componente da formulação de diversos produtos fitossanitários, a exemplo, os produtos Yield Plus ${ }^{\circledR}$ (Cryptococcus albidus) recomendado para o controle de patógenos de pós-colheita (Botrytis e Penicillium) em maçã e citrus, Shemer ${ }^{\circledR}$ (Metschnikowia fructicola) que previne o desenvolvimento de podridões causadas por fungos fitopatogênicos, incluindo: $P$. digitatum e P. italicum dos citros, P. expansum em frutos de caroço, etc (Bettiol, 2012).

O uso dos agentes de controle biológico como fungicidas analógicos aos sintéticos para reduzir as perdas pós-colheita têm sido foco de consideráveis pesquisas nos últimos 30 anos, mediante os seus múltiplos mecanismos de ação, sendo alternativas viáveis aos produtores, tendo em vista que a procura por métodos efetivos e amigáveis de controle de doenças é imprescindível (Wisniewski et al., 2016; Liu et al., 2018; Romanazzi et al., 2017).

\section{MECANISMOS DE AÇÃO BIOCONTROLADORA DAS LEVEDURAS}

Existe uma gama de micro-organismos utilizados no processo de biocontrole de frutos cítricos, porém, estes representam um número ínfimo comparado às espécies de leveduras conhecidas. Além disso, as cepas isoladas de diferentes fontes e lugares são diversas, podendo haver grandes diferenças na eficácia de seu biocontrole. Portanto, é necessário um grande número de estudos sobre leveduras envolvidas no processo de biocontrole. Quando utilizados como agentes de controle biológico, diferentes espécies de leveduras podem prevenir a infecção, diminuir a colonização do tecido hospedeiro e reduzir a sobrevivência e esporulação de patógenos com uma eficiência diferenciada (Punja \& Utkhede, 2003; Kupper et al., 2013; Liu et al., 2017).

Segundo relatos de $\mathrm{Xu}$ et al. (2013), as plantas desenvolvem uma complexa variedade de eventos que envolvem a síntese e acúmulo de novas proteínas que têm ação direta ou indireta durante a patogênese e a resistência induzida pelo hospedeiro, que pode ser um dos mecanismos utilizado por leveduras para controlar doenças de plantas. O sucesso do estabelecimento, atividade e proliferação de agentes de biocontrole fúngico depende de sua adaptação e desempenho dentro de sistemas físicos, biologicamente e espacialmente complexos, onde uma ampla gama de 
interações interespecíficas tróficas e não tróficas ocorrem (Knudsen \& Dandurand, 2014).

Os principais mecanismos de ação das leveduras durante o biocontrole em pós-colheita incluem a competição por espaço e nutrientes, produção de metabólitos voláteis, enzimas degradativas da parede celular de patógenos como a $\beta$-1,3-glucanase e a quitinase, indução de resistência ao hospedeiro, micoparasitismo, a produção da atividade Killer e representam um avanço no controle biológico de patógenos (Coelho et al., 2003; El-Tarabily \& Sivasithamparam, 2006).

No controle a patógenos que comprometem a viabilidade e a oferta de produtos agrícolas, as leveduras apresentam-se como importantes agentes de controle biológico, sendo que sua atividade de biocontrole relacionada à síntese de enzimas hidrolíticas tais como: glucanases, quitinases, proteases e $\mathrm{N}$-acetilglicosaminidase que degradam a parede celular de fitopatógenos reduzindo o seu potencial negativo tanto na pós-colheita de vegetais quanto em outros produtos alimentícios (Silva et al. 2011; Daguerre et al., 2014; Kubicek et al., 2001).

\section{PRODUÇÃO DE ENZIMAS HIDROLÍTICAS}

A parede celular fúngica é uma organela dinâmica que fornece estrutura, protege a viabilidade dos fungos além de controlar as interações com o hospedeiro durante o processo de infecção, é composta principalmente de polissacarídeos, sendo uma importante fonte de padrões moleculares associados a patógenos (Nishimura, 2016; Hopke et al., 2018).

Entre os principais polissacarídeos da parede celular destacam-se a quitina e os glucanos, a quitina é um componente estrutural essencial que confere rigidez à parede celular dos fungos para resistir a desafios químicos e físicos do meio. Os glucanos têm uma função estrutural, de armazenamento ou extracelular em certas plantas superiores, leveduras, algas, cogumelos, fungos, algas marrons e bactérias, são constituídos de polissacarídeos de monómeros de D-glicose, unidos por ligações glicosídicas (Fesel \& Zuccaro, 2016; Rieder et al., 2018).

Ressalta-se que dois grupos de glucanos estão presentes nos fungos, sendo estes os $\alpha$-glucanos e $\beta$-glucanos, os $\beta$-glucanos são polímeros de glicose encontrados na parede das células de levedura, estima-se que entre $65 \%$ a $90 \%$ do conteúdo total de $\beta$-glucano presentes na parede celular fúngicas sejam formados por $\beta$-1,3-glucano. Além disso, as $\beta-1,3$-glucanas podem atuar como moduladoras do sistema de defesa de plantas, sendo importantes na interação entre fungos fitopatogênicos e sua planta hospedeira (Bowman \& Free, 2006; Fesel \& Zuccaro, 2016; Geoghegan et al., 2017; Regla et al., 2018).

Endo- $\beta$-1,3-glucanase e endoquitinase, conhecida como PR2 e PR3, têm a capacidade de hidrolisar diretamente paredes celulares de fungos patógenos por clivagem de ligações $\beta$ em locais aleatórios ao longo da cadeia de polissacarídeos, libertam assim o $\beta$-1,3-glucano e a quitina compostos de oligossacarídeos que então estimulam as respostas de defesa do hospedeiro (Liu et al., 2016, Spadaro \& Droby, 2016).

A capacidade de produz enzimas de gradativas a parede celular de patógenos tais como exo- $\beta$-1,3-glucanases, quitinases e proteases pela levedura Candida oleophila, tornaram esse micro-organismo o principal componente do produto comercial aspire ${ }^{\circledR}$ que apresenta resultados significativos no biocontrole de fitopatógenos como $P$. digitatum em pós-colheita em diversas espécies de plantas (Bar-Shimon et al., 2004; Daguerre et al., 2014; Kubicek et al., 2001).

\section{A ação da enzima $\beta$-1,3-glucanase}

As $\beta$-glucanases, assim como outras enzimas hidro líticas, participam diretamente do processo de controle biológico em pós-colheita causada por fungos fitopatogênicos, porque hidrolisar $\beta-1,3-1,6$ glucanas constituintes da parede celular de alguns patógenos, o que é importante para inibir ou retardar a deterioração de frutos (Fleuri \& Sato, 2008; Iorio et al., 2008; Bauermeister et al., 2010).

A ação da enzima ocorre através de hidrólises sucessivas a partir da extremidade não-redutora da glucana, sendo laminarina e postulana usadas como substratos nos ensaios enzimáticos utilizados na determinação das atividades de $\beta-1,3$ e $\beta$-1-6- glucanases, respectivamente. A aplicação das $\beta$-1,3-glucanases em biotecnologia tem um futuro promissor, para novos processos industriais, podendo ser aplicadas na caracterização da parede celular microbiana, na indústria alimentícia, com o desenvolvimento de suplementos alimentares, na produção de bebidas e ração animal (Sutherland, 1999; Bauermeister et al., 2010; Costa \& Choupina, 2013).

Em bioprocessos agrícolas, a relação entre a expressão enzimática e a atividade antifúngica de leveduras, desempenha um papel muito importante no biocontrole de fitopatógenos como pode ser observado nas pesquisas realizadas por Hong et al. (2017), onde a levedura 
Wickerhamomyces anomalus ou Pichia anomala inibiu fortemente o crescimento de hifas dos patógenos Fusarium oxysporum e Rhizoctonia solani, podendo ser usado como um agente de controle biológico contra fitopatógenos e também como um bioinibidor do crescimento de células de levedura.

De acordo com estudos realizados sobre o comportamento enzimático por isolados de $S$. cerevisiae, Lopes et al. (2015) apontaram a produção das enzimas hidrolíticas $\beta$-1,3-glucanase, quitinase e a detecção da atividade killer como sendo os principais mecanismos de ação envolvidos no controle biológico da queda precoce de laranjas em pré-colheita de frutos cítricos causado por Colletotrichum acutatum.

Essa riqueza de relatórios científicos acumulados sobre $\beta$-1,3-glucanases ampliou o entendimento sobre a sua estrutura, a regulação da sua expressão e os múltiplos papéis que a enzima desempenha direta e indiretamente nas plantas, as $\beta$-1,3-glucanases são as mais estudadas em relação à sua expressão durante a infecção do patógeno e seu amplo espectro de actividade antimicrobiana e dos genes de defesa produzidos pela $\beta$-1,3-glucanase, o que respresesenta uma ferramenta potencial no arsenal da humanidade para a execusão de uma agricultura mais sustentável (Balasubramanian et al., 2012).

\section{ATIVIDADE KILLER}

Entre uma ampla variedade de leveduras antagônicas, uma atenção particular tem sido direcionada para o uso de leveduras que exibem um fenótipo assassino $\left(\mathrm{K}^{+}\right)$para o controle de podridões em pós-colheita de frutos, trata-se de um processo em que a levedura tem a capacidade de secretar proteínas assassinas ou toxinas assassinas, importantes no processo de controle biológico de fungos filamentosos, por receptores específicos da parede celular em micro-organismos suscetíveis sendo este processo denominado atividade killer (Grzegorczyk et al., 2017).

As leveduras produtoras dessas exotoxinas estão aptas a destruir células e atuam em organismos da mesma espécie ou espécies distintas, que são caracterizadas por estarem presentes em substratos com alta concentração de açúcar e baixo pH (Polonelli et al., 1993).

A atividade killer caracteriza-se pela produção de exotoxinas com atividade antimicrobiana, que são mediadas um processo em que a levedura tem a capacidade de secretar proteínas assassinas ou toxinas assassinas, importantes na atividade killer caracteriza-se pela produção de exotoxinas com atividade antimicrobiana, que são mediadas por receptores específicos da parede celular em micro-organismos suscetíveis. As leveduras produtoras dessas exotoxinas estão aptas a destruir células e atuam em organismos da mesma espécie ou espécies distintas, que são caracterizadas por estarem presentes em substratos com alta concentração de açúcar e baixo pH (Polonelli et al., 1993).

A produção de glicoproteínas com propriedades antifúngicas tais como a toxinas killer, é um fenômeno comum em vários gêneros de leveduras. A descrição do fenótipo killer foi realizada pela primeira vez em 1963 na levedura $S$. cerevisiae, sendo relatado que cepas de tais espécies poderiam ser classificadas em um dos três fenótipos: assassino, sensível e neutro mediante a produção da toxina (Bevan \& Makower, 1963; Somers \& Bevan, 1969; Sato et al., 1993; Ceccato-Antonini et al., 2004; Angioletto, 2013).

Contudo, a produção desta toxina não está restrita somente ao gênero Saccharomyces, ela também pode ser encontrada em outros gêneros de leveduras como: Cryptococcus, Candida, Hanseniaspora, Debaryomyces, Kluyveromyces, Hansenula, Pichia, Sporidiobolus, Zygosaccharomyces, Tilletiopsis, dentre outros, a capacidade de produção de toxina killer pode representar uma vantagem seletiva sobre espécies competidoras em um mesmo habitat (Sato et al., 1993; Soares \& Sato, 2000; Santos et al., 2009).

A atividade killer é um fenômeno que vem alcançando importantes reconhecimentos dentro dos mais diversos ramos industriais, sendo utilizadas no combate as perdas causadas por fungos fitopatogênicos, como por exemplo, o bolor negro causado por Aspergillus niger e o bolor verde causado $P$. digitatum em pós-colheita de limões, o que representa um importante mecanismo de ação envolvido no controle biológico dessas doenças e uma alternativa ao uso de produtos químicos sintéticos na agricultura (Perez et al., 2017; Ullivarri et al., 2018).

Cunha et al. (2018), analisando a produção desta toxina assassina por isolados de leveduras, confirmou os múltiplos modos de ação da levedura Candida stellimalicola contra o fungo $P$. italicum, apresentando a atividade killer, produção de enzimática e inibição da germinação de conídios do fungo em pós-colheita de citros o que pode explicar o controle do fitopatógeno.

No mesmo sentido, Perez et al. (2017) confirmaram a eficiência das leveduras Clavispora lusitaniae e Pichia fermentans frente ao fungo $P$. digitatum em pós-colheita de limões, mostrado que os mesmos foram eficazes no 
controle do avanço da doença indicando a presença da atividade killer por esses isolados como um importante mecanismo de controle biológico em comparação com fungicidas sintéticos IMZ, TBZ amplamente utilizados em pós-colheita de citros e um produto comercial a base da levedura Candida oleofila.

\section{CONCLUSÃO}

O biocontrole pós-colheita de podridão de $P$. digitatum através de levedura surge como uma alternativa promissora aos fungicidas sintéticos presentes no mercado, com menor impacto nas propriedades físico-químicas dos frutos. A presente revisão também revelou que estudos anteriores sobre o comportamento do agente de biocontrole são de fundamental importância para a redução desses produtos na agricultura. Sendo a atividade killer e a produção da enzima $\beta$-1,3-glucanase mecanismos fundamentais para o controle biológico de fitopatógenos. Portanto, precisa de mais estudos para estabelecer o efeito do antagonismo biológico nos atributos de qualidade de frutas e vegetais.

\section{REFERÊNCIAS}

Agência Nacional de Vigilância Sanitária. Diretoria Colegiada. (2016). Resolução $R D C n^{\circ}$ 60, de 3 de fevereiro de 2016. Brasília, DF: Diário Oficial da República Federativa do Brasil, seção 1, p. 48. Recuperado em 9 de janeiro de 2017, de http://pesquisa.in.gov.br/imprensa/jsp/visualiza/ index.jsp?.jornal $=1 \&$ pagina $=48 \&$ data $=04 / 02 / 2016$

Alves, R. R. (2017). Avaliação de resíduos dos fungicidas Imazalil e Procloraz aplicados em pós-colheita de goiabas 'Pedro Sato' (Tese de doutorado). Programa de Pós-graduação em Agronomia, Universidade Federal de Viçosa, Viçosa.

Amaral, J. D. (1982). Os citrinos (3. ed., 781 p.) Lisboa: Livraria Clássica Editora.

Andrade, M. J., Thorsen, L., Rodríguez, A., Córdoba, J. J., \& Jespersen, L., (2014). Inhibition of ochratoxigenic moulds by Debaryomyces hansenii strains for biopreservation of drycured meat products. International Journal of Food Microbiology, 170, 70-77.

Angioletto, E. (2013). Isolamento e caracterização de leveduras para produção de sidra (Dissertação de mestrado). Programa de Pós-graduação em Biotecnologia e Biociencia, Universidade Federal de Santa Catarina, Florianópolis.

Associação Brasileira das Empresas de Controle BiológicoABCBIO. (2016). Projeta expansão de mercado. Recuperado em 20 de agosto de 2016, de http://www.abcbio.org.br/ conteudo/publicações/associação-brasileira-das-empresas de-controle-biológico-projeta-expansão-de-mercado

Baker, L. F., \& Cook, R. J. (1974). Biological control of plant pathogens (433 p.). San Francisco: W. H. Freeman.

Balasubramanian, V., Vashisht, D., Cletus, J., \& Sakthivel, N. (2012). Plant b-1,3-glucanases: their biological functions and transgenic expression against phytopathogenic fungi. Biotechnology Letters, 34(11), 1983-1990. http://dx.doi. org/10.1007/s10529-012-1012-6. PMid:22850791.

Bar-Shimon, M., Yehuda, H., Cohen, L., Weiss, B., Kobeshnikov, A., Daus, A., Goldway, M., Wisniewski, M., \& Droby, S. (2004). Characterization of extracellular lytic enzymes produced by the yeast biocontrol agent Candida oleophila. Current Genetics, 45(3), 140-148. http://dx.doi. org/10.1007/s00294-003-0471-7. PMid:14716497.

Bauermeister, A., Rezende, M. I., Giese, E. C., Dekker, F. R. H., \& Barbosa, A. M. (2010). $\beta-1,3-G l u c a n a s e s$ fúngicas: produção e aplicações biotecnológicas. Ciências Exatas e Tecnológicas, 31(2), 75-86. http://dx.doi. org/10.5433/1679-0375.2010v31n2p75.

Bautista-Baños, S., Sivakumar, D., Bello-Pérez, A., Villanueva-Arce, R., \& Hernández-López, M. (2013). A review of the management alternatives for controlling fungi on papaya fruit during the postharvest supply chain. Crop Protection (Guildford, Surrey), 49, 8-20. http:// dx.doi.org/10.1016/j.cropro.2013.02.011.

Belo, A. P. (2017). Caracterização sensorial e físicoquímica de tangerinas produzidas em Goiás. (Tese de doutorado). Programa de Pós-graduação em Agronomia, Universidade Federal de Goiás, Goiânia.

Bettiol, W., Morandi, M. A. B., Pinto, Z. V., Paula Júnior, T. J., Corrêa, É. B., Moura, A. B., Lucon, C. M. M., Costa, J. C. B., \& Bezerra, J. L. (2012). Produtos comerciais à base de agentes de biocontrole de doenças de plantas (pp. 155, Vol. 88, Documentos). Jaguariúna, SP: Embrapa Meio Ambiente.

Bevan, E. A., \& Makower, M. (1963). The physiological basis of the killer-character in yeast. In S. J. Geerts (Ed.), Genetics today: proceedings of the XI International 
Congress of Genetics (Vol. 1, pp. 202-203). Oxford: Pergamon Press.

Borges, A. C. G., \& Costa, V. M. H. M. (2006). A evolução do agronegócio citrícola paulista e o perfil da intervenção do estado. Revista Uniara, 17/18.

Bowman, S. M., \& Free, S. J. (2006). The structure and synthesis of the fungal cell wall. BioEssays, 8(8), 799-808. http://dx.doi.org/10.1002/bies.20441. PMid:16927300.

Brasil. Ministério da Saúde. Agência Nacional de Vigilância Sanitária - ANVISA. Diretoria Colegiada. (2016). Resolução RDC $n^{\circ}$ 60, de 3 de fevereiro de 2016. Brasília, DF: Diário Oficial da República Federativa do Brasil, no. 24, seção 1, p. 48. Recuperado em 9 de janeiro de 2017, de http://pesquisa.in.gov.br/imprensa/jsp/visualiza/index. jsp? jornal $=1 \&$ pagina $=48 \&$ data $=04 / 02 / 2016$

Broetto, L., Coltro-Roncato, S., Meinerz, C. C., Dildey, O. D. F., Pazdiora, P. C., Gonçalves, E. D. V., Moraes, A. J., Henkemeier, N. P., Kuhn, O. J., \& Stangarlin, J. R. (2014). Crescimento micelial e produção de microescleródios de macrophomina phaseolina confrontado com diferentes isolados de Trichoderma sp. Scientia Agrária Paranaensis, 13(4), 310-317. http://dx.doi.org/10.18188/1983-1471/ sap.v13n4p310-317.

Calvo-Garrido, C., Viñas, I., Elmer, P. A. G., Usall, J., \& Teixidò, N. (2014). Suppression of Botrytis cinerea on nectrotic grapevine tissues by early season applications of natural products and biocontrol agents. Pest Management Science, 70, 595-602. PMid:23744713.

Carvalho, W. S. G. (2017). Eficiência produtiva e porte de cultivares de citros enxertadas sobre os porta-enxertos limoeiro cravo e flying dragon, em cultivo irrigado (Dissertação de mestrado). Centro de Ciência e Tecnologia Agropecuária, Universidade Estadual do Norte Fluminense Darcy Riberio, Campos dos Goytacazes

Carvalho, D. D. C., Geraldine, A. M., Lobo Junior, M., \& Mello, S. C. M. (2015). Biological control of white mold by Trichoderma harzianum in common bean under field conditions. Pesquisa Agropecuária Brasileira, 50(12), 1220-1224. http://dx.doi.org/10.1590/ S0100-204X2015001200012.

Ceccato-Antonini, S. R., Tosta, C. D., \& Silva, A. C. (2004). Determination of yeast Killer activity in fermentation sugarcane juice using selected ethanol-making strains. Brazilian Archives of Biology and Technology, 47(1), 13-23. http://dx.doi.org/10.1590/S1516-89132004000100003.
Centro de Estudos Avançados em Economia Aplicada CEPEA. (2018). Recuperado em 15 de março de 2018, de https://www.cepea.esalq.usp.br

Cerioni, L., Lazarte, M. L., Villegas, J. M., RodríguezMontelongo, L., \& Volentini, S. I. (2013). Inhibition of Penicillium expansum by an oxidative treatment. Food Microbiology, 33(2), 298-301. http://dx.doi.org/10.1016/j. fm.2012.09.011. PMid:23200664.

Coelho, A. R., Hoffmann, F. L., \& Hirooka, E. Y. (2003). Biocontrol by yeasts: perspectives in aplication for fruits safety: a review. Semina: Ciências Agrárias, 24, 337-358.

Companhia Nacional de Abastecimento - CONAB. (2017). Proposta de preços mínimos/safra 2016-2017 (Vol. 2, No. 1). Brasília: CONAB.

Córdova, N. M., Mendoza, S. R., Montiel, L. G. H., \& Ângulo, C. (2018). The potential use of Debaryomyces hansenii for the biological control of pathogenic fungi in food. Biological Control, 121, 216-222. http://dx.doi. org/10.1016/j.biocontrol.2018.03.002.

Costa, C. C., Guilhoto, J. J. M., \& Burnquist, H. L. (2015). Impactos econômicos de reduções nas perdas pós-colheita de produtos agrícolas no Brasil. Revista de Economia e Sociologia Rural, 53(3), 395-408. http:// dx.doi.org/10.1590/1234-56781806-9479005303002.

Costa, R. A. F., \& Choupina, A. B. (2013). Enzimas $\beta$-Glucanases: aplicações da hidrólise de polis sacarídeos / $\beta$-Glucanases enzymes. Appliance of polysaccharides hydrolisis. Revista Eletrônica de Biologia, 6, 205-213.

Cunha, T., Ferraz, L. P., Wehr, P. P., \& Kupper, K. C. (2018). Antifungal activity and action mechanisms of yeasts isolates from citrus against Penicillium italicum. International Journal of Food Microbiology, 276, 20-27.

Daguerre, Y., Siegel, K., Edel-Hermann, V., \& Steinberg, C. (2014). Fungal proteins and genes associated with biocontrol mechanisms of soil-borne pathogens: a review. Fungal Biology Reviews, 28(4), 97-125. http://dx.doi. org/10.1016/j.fbr.2014.11.001.

Dantas, S. A. F., Oliveira, S. M. A., Michereff, S. J., Nascimento, L. C., Gurgel, L. M. S., \& Pessoa, W. R. L. S. (2003). Doenças fúngicas pós-colheita em mamões e laranjas comercializados na Central de Abastecimento do Recife. Fitopatologia Brasileira, Brasilia, 28(5), 528-533. http://dx.doi.org/10.1590/S0100-41582003000500010.

Delonge, M. S., Miles, A., \& Carlisle, L. (2016). Investing in the transition to sustainable agriculture. Environmental 
Science \& Policy, 55(2), 266-273. http://dx.doi.org/10.1016/j. envsci.2015.09.013.

Diehl, M., Ferla, N. J., \& Johann, L. (2012). Plantas associadas à videiras: uma estratégia para controle biológico no Rio Grande do Sul. Arquivos do Instituto Biológico, 79(4), 579-586. http://dx.doi.org/10.1590/ S1808-16572012000400015.

Donadio, L. C., Mourão Filho, F. A. A., \& Morreira, C. S. (2005). Centro de origem, distribuição geográfica das plantas cítricas e histórico da citricultura no Brasil. In D. Mattos Junior, J. D. Negri, R. M. Pio, \& Pompeu Junior J. (Eds.), Citros (pp. 3-18.). Campinas: Editora AC/Fundag.

Droby, S., Cohen, L., Daus, A., Weiss, B., Horev, B., Chalutz, E., Katz, H., Keren-Tzur, M., \& Shachnai, A. (1998). Commercial testing of Aspire: a yeast preparation for the biological control of postharvest decay of citrus. Biological Control, 12(2), 97-101. http://dx.doi.org/10.1006/ bcon.1998.0615.

Dudley, N., Attwood, S. J., Goulson, D., Jarvis, D., Bharucha, Z. P., \& Pretty, J. (2017). How should conservationists respond to pesticides as a driver of biodiversity loss in agroecosystems. Biological Conservation, 209(3), 449453. http://dx.doi.org/10.1016/j.biocon.2017.03.012.

Eckert, J. W. (1993). Post-harvest diseases of citrus fruits. Agriculture Outlook, 54, 225-232.

Eckert, J. W., \& Brown, G. E. (1986). Post-harvest citrus disease and their control. In W. F. Wardowski, S. Nagy, \& W. Grierson (Eds.), Fresh citrus fruits (pp. 315-353). New York: Van Nostrand Reinhold Company. http:// dx.doi.org/10.1007/978-1-4684-8792-3_13.

El-Tarabily, K. A., \& Sivasithamparam, K. (2006). Potential of yeasts as biocontrol agents of soil-borne fungal plant pathoge ns and as plant growth promoters. Mycoscience, 47(1), 25-35. http://dx.doi.org/10.1007/ S10267-005-0268-2.

Erasmus, A., Lennox, C. L., Jordaan, H., Smilanick, J. L., Lesar, K., \& Fourie, P. H. (2011). Imazalil residue loading and green mould control in citrus packhouses. Postharvest Biology and Technology, 62(2), 193-203. http://dx.doi.org/10.1016/j.postharvbio.2011.05.006.

Estrada, R. R. G., Millan, E. C., Sánchez, J. A. R., Rosales, P. U. B., \& Santoyo, M. C. (2017). Control of blue mold decay on Persian lime: application of covalently crosslinked arabinoxylans bioactive coatings with antagonistic yeast entrapped. LWT - Food Science and Technology, 85(Pt A), 187-196.
Fang, Q., \& Tian, S. P. (2000). Postharvest biological control of Rhizopus rot of nectarine fruits by Pichia membranefaciens. Plant Disease, 84(11), 1212-1216. http://dx.doi.org/10.1094/PDIS.2000.84.11.1212. PMid:30832169.

Ferraz, L.P., Cunha, T., \& Kupper, K. C. (2018). Mecanismos de ação de isolados de leveduras envolvidos no biocontrole de Penicillium digitatum, agente causal do bolor verde em frutos cítricos. Citrus Research \& Technology, 39, 1-11. http://dx.doi.org/10.4322/crt.17101.

Fesel, P. H., \& Zuccaro, A. (2016). $\beta$-glucan: crucial component of the fungal cell wall and elusive MAMP in plants. Fungal Genetics and Biology, 90, 53-60. http:// dx.doi.org/10.1016/j.fgb.2015.12.004. PMid:26688467.

Feyder, S., De Craene, J. O., Bär, S., Bertazzi, D. L., \& Friant, S. (2015). Membrane trafficking in the yeast Saccharomyces cerevisiae Model. International Journal of Molecular Sciences, 16(1), 1509-1525. http://dx.doi. org/10.3390/ijms16011509. PMid:25584613.

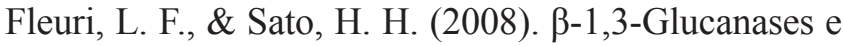
quitinases: aplicação na lise de leveduras e inibição de fungos. Ciência e Agrotecnologia, 32(4), 1224-1231.

Fiori, S., Urgeghe, P. P., Hammami, W., Razzu, S., Jaoua, S., \& Migheli, Q. (2014). Biocontrol activity of four non-and low-fermenting yeast strains against Aspergillus carbonarius and their ability to remove ochratoxin A from grape juice. International. Journal of Food Microbiology., 189, 45-50. http://dx.doi.org/10.1016/j.ijfoodmicro.2014.07.020. PMid:25113045.

Fischer, I. H., Toffano, L., Lourenço, S. A., \& Amorim, L. (2007). Caracterização dos danos pós-colheita em citrosprocedentes de "Packinghouse". Fitopatologia Brasileira, (32), 304-310

Fischer, I. H., Lourenço, S. A., \& Amorim, L. (2008). Doenças pós-colheita em citros e caracterização da população fúngica ambiental no mercado atacadista de são paulo. Tropical Plant Pathology, 33(3), 219-226

Fischer, I. H., Palharini, M. C. A., Spósito, M. B., \& Amorim, L. (2013). Doenças pós-colheita em laranja 'Pêra' produzida em sistema orgânico e convencional e resistência de Penicillium digitatum a fungicidas. Summa Phytopathologica, 39(1), 28-34. http://dx.doi.org/10.1590/ S0100-54052013000100005.

Fonseca, A. E. (2017). Controle da mancha preta dos citros via fungicida cúprico e validação da produção de frutos cítricos em área não livre da doença: estudo de 
caso. (Tese de doutorado). Faculdade de Ciências Agrárias e Veterinarias, Universidade Estadual Paulista "Júlio de Mesquita Filho", Jaboticabal.

Food and Agriculture Organization of the United Nations -- FAO. (2016). Citrus fruit fresh and processed: annual statistics 2012. Geneva: FAO. Recuperado em 30 de janeiro 2017, de http://www.fao.org/fileadmin/templates/est/ COMM_MARKETS_MONITOR ING/Citrus/Documents/ CITRUS_BULLETIN_2012.pdf

França, G. S. (2016). Potencial de leveduras no controle biológico da podridão-verde do inhame (Dissertação de mestrado). Universidade Federal Rural de Pernambuco, Recife.

Franco, D. A. S., \& Bettiol, W. (2002). Efeito de produtos alternativos para o controle do bolor verde (penicillium digitatum) em pós-colheita de citros. Revista Brasileira de Fruticultura, 24(2), 569-572.

Frisvad, J. C., \& Samson, R. A. (2004). Polyphasic taxonomy of Penicillium subgenus Penicillium: a guide to identification of food and air-bone terverticilliate penicillia and their mycotoxins. Studies in Mycology, 49, 1-173.

Fundo de Defesa da Citricultura - FUNDECITRUS. (2019). Inventário de árvores e estimativa da safra de laranja 2019/2020 do cinturão citrícola de São Paulo e Triângulo/Sudoeste Mineiro (136 p.). Araraquara: Fundecitrus.

Gatto, M. A., Ippolito, A., Linsalata, V., Cascarano, N. A., Nigro, F., Vanadia, S., \& Di Venere, D. (2011). Activity of extracts from wild edible herbs against postharvest fungal diseases of fruit and vegetables. Postharvest Biology and Technology, 61(1), 72-82. http://dx.doi.org/10.1016/j. postharvbio.2011.02.005.

Geoghegan, I., Steinberg, G., Gurr, S. (2017). The role of the fungal cell wall in the infection of plants. Trends in Microbiology, 25(12), 957-967.

Germplasm Resources Information Network - GRIN. (2013). Citrus. Recuperado em 13 de maio de 2013, http://jornals.ashs.org/hortsci/view/journals/hortsci/48/3/ article-p330.xml.

Gholamnejad, J., Etebarian, H. R., \& Sahebani, N. (2010). Biological control of apple blue mold with Candida membranifaciens and Rhodotorula mucilaginosa. African Journal of Food Science, 4(1), 001-007.

Ghorbanpour, M., Omidvari, M., Abbaszadeh-Dahaji, P., Omidvar, R., \& Kariman, K. (2018). Mechanisms underlying the protective effects of beneficial fungi against plant diseases. Biological Control, 117, 147-157. http:// dx.doi.org/10.1016/j.biocontrol.2017.11.006.

GLOBALG.A.P. (2018). GlobalGAP Certification. Recuperado em 27 de fevereiro de 2018, de globalgap. org/uk_en/index.html

Gomes, P. (1972). Fruticultura Brasileira (pp. 172-192). São Paulo: Nobel.

Grzegorczyk, M., Zarowska, B., Restuccia, C., \& Cirvilleri, C. (2017). Postharvest biocontrol ability of killer yeasts against Monilinia fructigena and Monilinia fructicola on stone fruit. Food Microbiology, 61, 93-101. http://dx.doi. org/10.1016/j.fm.2016.09.005. PMid:27697174.

Heneberg, P., Svoboda, J., \& Pech, P. (2018). Benzimidazole fungicides are detrimental to common farmland ants. Biological Conservation, 221, 114-117. http://dx.doi. org/10.1016/j.biocon.2018.03.004.

Hetherington, A. C., \& Raistrick, H. (1931). Studies in the biochemistry of microorganisms. XIV. On the production and chemical constitution of a new yellow colouring matter, citrinin, produced from glucose by Penicillium citrinum Thom. Philosophical Transactions of the Royal Society of London. Series B, Biological Sciences, 220, 269-295.

Hong, S. H., Song, Y. S., Seo, D. J., Kim, K. Y., \& Jung, W. J. (2017). Antifungal activity and expression patterns of extracellular chitinase and b-1,3-glucanase in Wickerhamomyces anomalus EG2 treated with chitin and glucan. Microbial Pathogenesis, 110, 159-164. http://dx.doi. org/10.1016/j.micpath.2017.06.038. PMid:28668604.

Hopke, A., Brown, A. J. O., Hall, R. A., \& Wheeler, R. T. T. (2018). Dynamic fungal cell wall architecture in stress adaptation and immune evasion. Trends in Microbiology, 26(4), 284-295.

Houbraken, J., Visagie, C. M., Meijer, M., Frisvad, J. C., Busby, P. E., Pitt, J. I., Seifert, K. A., Louis-Seize, G., Demirel, R., Yilmaz, N., Jacobs, K., Christensen, M., \& Samson, R. A. (2014). A taxonomic and phylogenetic revision of Penicillium section Aspergilloides. Studies in Mycology, 78, 373-451. http://dx.doi.org/10.1016/j. simyco.2014.09.002. PMid:25492984.

Human Right Watch - HRW. (2018). Você não quer mais respirar veneno As falhas do Brasil na proteção de comunidades rurais expostas à dispersão de agrotóxicos (60 p., Relatório). São Paulo: HRW. Recuperado em 9 de janeiro de 2017, de http://www.hrw.org /pt 
Instituto Brasileiro de Geografia e Estatística - IBGE. (2013). Produção agrícola municipal (102 p). Rio de Janeiro: IBGE.

Instituto Brasileiro de Geografia e Estatística - IBGE. (2015). Levantamento Sistemático da Produção Agrícola (LSPA) (pp. 83). Rio de Janeiro: IBGE. Recuperado em 22 de fevereiro de 2015, de http://www.ibge.gov.br/home/ estatistica/indicadores/agropecuaria/lspa/lspa_201502_ 4.shtm

Instituto Brasileiro de Geografia e Estatística - IBGE. (2017). Levantamento sistematico da produção agrícola. Rio de Janeiro: IBGE. Recuperado em 27 de setembro de 2017, de http://sidra.ibge.gov.br/tabela/1618\#notas-tabelas

Iorio, E., Torosantucci, A., Bromuro, C., Chiani, P., Ferretti, A., Giannini, M., Cassone, A., \& Podo, F. (2008). Candida albicans cell wall comprises a branched $\beta$-D$(1,6)$-glucan with $\beta$-D-(1,3)side chains. Carbohydrate Research, 343(6), 105-1061. http://dx.doi.org/10.1016/j. carres.2008.02.020. PMid:18346722.

Jatoi, M. A., Juric, S., Vidrih, R., Vincekovic, M., Vukovic, M., \& Jemric, T. (2017). The effects of postharvest application of lecithin to improve storage potential and quality of fresh goji (Lycium barbarum L.) berries. Food Chemistry, 230, 241-249. http://dx.doi.org/10.1016/j. foodchem.2017.03.039. PMid:28407907.

Jin, Y., Zhu, Z., Wang, Y., Yang, E., Feng, X., \& Fu, Z. (2016). The fungicide imazalil induces developmental abnormalities and alters locomotor activity during early developmental stages in zebrafish. Chemosphere, 153, 455461. http://dx.doi.org/10.1016/j.chemosphere.2016.03.085. PMid:27035382.

Kanetis, L., Förster, H., \& Adaskaveg, J. E. (2018). Comparative efficacy of the new postharvest fungicides azoxystrobin, fludioxonil, and pyrimethanil for managing citrus green mold. Plant Disease, 91(11), 1502-1511. http:// dx.doi.org/10.1094/PDIS-91-11-1502. PMid:30780742.

Karim, H., Boubaker, H., Askarne, L., Talibi, I., Msanda, F., Boudyach, E. H., Saadi, B., \& Ait Ben Aoumar, A. (2015). Antifungal properties of organic extracts of eight Cistus L. species against postharvest citrus sour rot. Letters in Applied Microbiology, 1(1), 16-22. http:// dx.doi.org/10.1111/lam.12507. PMid:26458008.

Kellerman, M., Joubert, J., Erasmus, A., \& Fourie, P. H. (2016). The effect of temperature, exposure time and $\mathrm{pH}$ on imazalil residue loading and green mould control on citrus through dip application. Postharvest Biology and
Technology, 121, 159-164. http://dx.doi.org/10.1016/j. postharvbio.2016.06.014.

Knudsen, G. R., \& Dandurand, L. C. (2014). Ecological complexity and the success of fungal biological control agentes. Advances in Agriculture, 1-11.

Koller, O. C. (1994). Citricultura: laranja, limão e tangerina (pp. 446). Porto Alegre: Rigel.

Kubicek, C., Mach, R. L., Peterbauer, C. K., \& Lorito, M. (2001). Trichoderma: from genes to biocontrol. Journal of Plant Pathology, 83(2001), 11-23.

Kupper, K. C., Cervantes, A. L. L., Klein, M. N., \& Silva, A. C. (2013). Avaliação de micro-organismos antagônicos, Saccharomyces cerevisiae e Bacillus subtilis para o controle de Penicillium digitatum. Revista Brasileira de Fruticultura, 35(2), 20-31. http://dx.doi.org/10.1590/ S0100-29452013000200011.

Lahlali, R., Hamadi, Y. E. L., Guilli, M., \& Jijakli, M. H. (2011). Efficacy assessment of Pichia guilliermondii strain Z1, a new biocontrol agent, against citrus blue mould in Morocco under the influence of temperature and relative humidity. Biological Control, 56(3), 217224. http://dx.doi.org/10.1016/j.biocontrol.2010.12.001.

Lamovšek, J., Urek, G., \& Trdan, S. (2013). Biological control of root-knot nematodes (Meloidogyne spp.): microbes against the pests. Acta Agriculturae Slovenica, 101(2), 263-275.

Li, W., Zhang, H., Li, P., Apaliya, M. T., Yang, Q., Peng, Y., \& Zhang, X. (2016). Biocontrol of postharvest green mold of oranges by Hanseniaspora uvarum Y3 in combination with phosphatidylcholine. Biological Control, 103, 30-38.

Liu, H., Guo, J., Cheng, Y., Liu, P., Long, C., \& Deng, B. (2010). Inhibitory activity of tea polyphenol and Hanseniaspora uvarum against Botrytis cinerea infections. Letters in Applied Microbiology, 51(3), 258-263. http://dx.doi.org/10.1111/j.1472-765X.2010.02888.x. PMid:20633212.

Liu, J., Sui, Y., Wisniewki, M., Droby, S., \& Liu, Y. (2013). Review: utilization of antagonistic yeasts to manage postharvest fungal diseases of fruit. International Journal of Food Microbiology, 167(2), 153-160. http://dx.doi. org/10.1016/j.ijfoodmicro.2013.09.004. PMid:24135671.

Liu, J., Sui, Y., Wisniewski, M., Xie, Z., Liu, Y., You, Y., Zhang, X., Sun, Z., Li, W., Li, Y., \& Wang, Q. (2018). The impact of the postharvest environment on the viability 
and virulence of decay fungi. Critical Reviews in Food Science and Nutrition, 58(10), 1681-1687. PMid:28140651.

Liu, Y. Q., Wisniewski, M., Kennedy, J. F., Jiang, Y. S., Tang, J. M., \& Liu, J. (2016). Chitosan and oligochitosan enhance ginger (Zingiber officinale Roscoe) resistance to rhizome rot caused by Fusarium oxysporum in storage. Carbohydrate Polymers, 151, 474-479. http://dx.doi. org/10.1016/j.carbpol.2016.05.103. PMid:27474591.

Liu, Y., Wang, W., Zhou, Y., Yao, S., Deng, L., \& Zeng, K. (2017). Isolation, identification and in vitro screening of chongqing orangery yeasts for the biocontrol of Penicillium digitatum on citrus fruit. Biological Control, 110, 18-24. http://dx.doi.org/10.1016/j.biocontrol.2017.04.002.

Liu, Y., Yao, S., Deng, L., Ming, J., \& Zeng, K. (2019). Different mechanisms of action of isolated epiphytic yeasts against Penicillium digitatum and Penicillium italicum on citrus fruit. Postharvest Biology and Technology, 152, 100110. http://dx.doi.org/10.1016/j.postharvbio.2019.03.002.

Lopes, M. R., Klein, M. N., Ferraz, L. P., Silva, A. C., \& Kupper, K. C. (2015). Saccharomyces cerevisiae: a novel and efficient biological control agent for Colletotrichum acutatum during pre-harvest. Microbiological Research, 175, 1-33. http://dx.doi.org/10.1016/j.micres.2015.04.003. PMid:25960430.

Lorenzi, H., Bacher, L., Lacerda, M., \& Sartori, S. (2006). Frutas brasileiras e exóticas cultivadas: de consumo in natura (674 p.). Nova Odessa: Editora Nova Odessa, Instituto Plantarum de Estudos da Flora.

Maro, L. A. C. (2010). Controle do bolor verde em citros com produtos alternativos aos agroquímicos (Dissertação de mestrado). Programa de Pós-graduação em Fitotecnia, Universidade Federal de Viçosa, Viçosa.

Martín, J. F. G., Olmo, M., \& García, J. M. (2018). Effect of ozone treatment on postharvest disease and quality of different citrus varieties at laboratory and at industrial facility. Postharvest Biology and Technology, 137, 77-85. http://dx.doi.org/10.1016/j.postharvbio.2017.11.015.

Medeiros, R. C., Musser, R. S., Silva, M. M., Santos, J. P. O., \& Nascimento Júnior, I. R. (2013). Análise exploratória das características morfológicas e qualitativas de variedades de laranjeiras de mesa da coleção em brejão-PE. Revista Brasileira de Fruticultura, 35(2), 500-507. http://dx.doi. org/10.1590/S0100-29452013000200020.

Medina, A., Mohale, S., Samsudin, N. I. P., RodriguezSixtos, A., Rodriguez, A., \& Magan, N. (2017). Biocontrol of Mycotoxins: dynamics and mechanisms of action. Current Opinion in Food Science, 17, 41-48. http://dx.doi. org/10.1016/j.cofs.2017.09.008.

Ministério da Agricultura, Pecuária e Abastecimento - MAPA. (2016). Cultura de citros. Brasília: MAPA. Recuperado em 22 de outubro de 2016, de http://www. agricultura.gov.br/vegetal/ culturas/citrus

Montiel, L. G. H., Perez, E. D. G., \& Amador, B. M., Vero, S., Contreras, R. G. C., \& Enriquez, G. R. (2018). Mechanisms employed by Debaryomyces hansenii in biological control of anthracnose disease on papaya fruit. Postharvest Biology and Technology, 139, 31-37.

Moretto, C., Cervantes, A. L. L., Batista Filho, A., \& Kupper, K. C. (2014). Integrated control of green mold to reduce chemical treatment in post-harvest citrus fruits Sci. Hortic, 165, 433-438. http://dx.doi.org/10.1016/j. scienta.2013.11.019.

Neves, M. F., \& Trombin, V. G. (2017). Anuário da fruticultura (60 p.). São Paulo: CITRUSBR.

Neves, M. F., Trombin, V. G., Milan, P., Lopes, F. F., Cressoni, F., \& Kalaki, R. (2010). O retrato da citricultura brasileira (Vol. 1, 137 p.). São Paulo: Independente.

Nishimura, M. (2016). Cell wall reorganization during infection in fungal plant pathogens. Physiological and Molecular Plant Pathology, 95, 14-19. http://dx.doi. org/10.1016/j.pmpp.2016.03.005.

Njombolwana, N. S., Erasmus, A., \& Fourie, P. H. (2013). Evaluation of curative and protective control of Penicillium digitatum following imazalil application in wax coating. Postharvest Biology and Technology, 77, 102-110. http:// dx.doi.org/10.1016/j.postharvbio.2012.11.009.

Núñez, F., Lara, M. S., Peromingo, B., Delgado, J., Sánchez-Montero, L., \& Andrade, M. J. (2015). Selection and evaluation of Debaryomyces hansenii isolates as potential bioprotective agents against toxigenic penicillia in dry-fermented sausages. Food Microbiology, 46, 114-120. http://dx.doi.org/10.1016/j.fm.2014.07.019. PMid:25475274.

O'Kennedy, M. M., Crampton, B. G., Lorito, M., Chakauya, E., Breese, W. A., Burger, J. T., \& Botha, F. C. (2011). Expression of a $\beta$-1,3-glucanase from a biocontrol fungus in transgenic pearl millet. South African Journal of Botany, 77(2), 335-345. http://dx.doi.org/10.1016/j. sajb.2010.09.016. 
Oliveira Junior, R. D. (2015). Seleção de Citrus spp. quanto ao desenvolvimento e qualidade de frutos para o Agreste Pernambucano (Dissertação de mestrado). Pós-graduação em Agronomia-Melhoramento Genético de plantas, Universidade Federal Rural de Pernambuco, Recife.

Oliveira, I. P., Oliveira, L. C., \& Moura, C. S. F. T. (2012). Frutas cítricas. Revista Faculdade Montes Belos, 5, 4.

Passos, O. S., Almeida, C. O., \& Peixoto, L. S. (2005). Potencialidade da Chapada Diamantina para citricultura. Bahia Agrícola, 7, 1-3.

Perez, M. F., Perez Ibarreche, J., Isas, A. S., Sepulveda, M., Ramallo, J., \& Dib, J. R. (2017). Antagonistic yeasts for the biological control of Penicillium digitatum on lemons stored under export conditions. Biological Control, 115, 135-140. http://dx.doi.org/10.1016/j.biocontrol.2017.10.006.

Piati, A., Nozaki, M. H., \& Schneide, C. F. (2013). Efeito do óleo essencial de eucalipto sobre Penicillium digitatum. Revista Acadêmica Ciências Agrárias e Ambientais, 11(Supl. 2), S19-S26.

Pereira, A. C. S. (2009). Qualidade, compostos bioativos $e$ atividade antioxidante total de frutas tropicais $e$ cítricas produzidas no Ceará (Dissertação de mestrado). Programa de Pós-graduação em Tecnologia de Alimentos, Universidade Federal do Ceará, Fortaleza

Pitt, J. I. (1979). The genus Penicillium and its teleomorphic states Eupenicillium and Talaromyces (pp. 1-634). London: Academic.

Polonelli, L., Conti, S., Gerloni, M., Magliani, W., Castagnola, M., \& Lucas, A. P. (1993). Acerola: suco da saúde conquista o mundo inteiro. Manchete Rural, 5(69), 10-13.

Praneetvatakul, S., Schreinemachers, P., Pananurak, P., \& Tipraqsa, P. (2013). Pesticides, external costs and policy options for Thai agriculture. Environmental Science \& Policy, 27(9), 103-113. http://dx.doi.org/10.1016/j. envsci.2012.10.019.

Prusky, D., Alkan, N., Mengiste, T., \& Fluhr, R. (2013). Quiescent and necrotrophic lifestyle choice during postharvest disease development. Annual Review of Phytopathology, 51(1), 155-176. http://dx.doi.org/10.1146/ annurev-phyto-082712-102349. PMid:23682917.

Punja, Z. K., \& Utkhede, R. S. (2003). Utilizando fungos e leveduras para controlar doenças das culturas de vegetais.
Trends in Biotechnology, 21(9), 400-407. http://dx.doi. org/10.1016/S0167-7799(03)00193-8. PMid:12948673.

Qin, X., Xiao, H., Xue, C., Yu, Z., Yang, R., Cai, Z., \& $\mathrm{Si}$, L. (2015). Biocontrol of gray mold in grapes with the yeast Hanseniaspora uvarum alone and in combination with salicylic acid or sodium bicarbonate. Postharvest Biology and Technology, 100, 160-167. http://dx.doi. org/10.1016/j.postharvbio.2014.09.010.

Regla, M. M. G., Ortega-Villaizan, M. D. M., Mercado, L., Novoa, B., Coll, J., \& Perez, L. (2018). Beta-glucan enhances the response to SVCV infection in zebrafish. Developmental and Comparative Immunology, 84, 307-314. http://dx.doi.org/10.1016/j.dci.2018.02.019. PMid:29524446.

Reuther, W. (1973). Climate and citrus behavior. In W. Reuther (Ed.), The citrus industry (Vol. 3, Cap. 9, pp. 280-337). Riverside: University of California.

Rieder, A., Ballance, S., B’ocker, U., \& Knutsen, S. (2018). Quantification of 1,3--D-glucan from yeast added as a functional ingredient to bread. Carbohydrate Polymers, 181, 34-42.

Rocha, J. G., \& Cassino, P. C. R. (2017). Fenologia de tangerina cv. Ponkan (Citrus reticulata Blanco) correlacionada aos insetos-pragas e predadores. Revista Agropecuária Técnica, 38(3), 142-146. http://dx.doi. org/10.25066/agrotec.v38i3.28820.

Romanazzi, G., Feliziani, E., Baños, S. B., \& Sivakumar, D. (2017). Shelf life extension of fresh fruit and vegetables by chitosan treatment. Critical Reviews in Food Science and Nutrition, 57(3), 579-601. PMid:26047630.

Santos, A., San Mauro, M., Bravo, E., \& Marquina, D. (2009). PMKT2, a new killer toxin from Pichia membranifaciens, and its promising biotechnological properties for control of the spoilage yeast Brettanomyces bruxellensis. Microbiology, 155(Pt 2), 624-634. http:// dx.doi.org/10.1099/mic.0.023663-0. PMid:19202111.

Sato, H. H., Pastore, G. M., \& Park, Y. K. (1993). Study some characteristics of newly isolated killer yeast. Revista de Microbiologia, 24, 71-72.

Sharma, K., Mahato, N., Cho, M. H., \& Lee, Y. R. (2017). Converting citrus wastes into value-added products: Economic and environmently friendly approaches. Nutrition (Burbank, Los Angeles County, Calif.), 34, 29-46. http:// dx.doi.org/10.1016/j.nut.2016.09.006. PMid:28063510. 
Sharma, R. R., Singh, D., \& Singh, R. (2009). Biological control of postharvest diseases of fruits and vegetables by microbial antagonists: A review. Biological Control, 50(3), 205-222. http://dx.doi.org/10.1016/j.biocontrol.2009.05.001.

Silva, B. D., Ulhoa, C. J., Batista, K. A., Yamashita, F., \& Fernandes, K. F. (2011). Potentital fungal inhibition by immobilized hydrolytic enzymes from Trichoderma asperellum. Journal of Agricutural and Food Chemistry, 59, 8148-8154.

Simas, D. L. R., de Amorim, S. H. B. M., Goulart, F. R. V., Alviano, C. S., Alviano, D. S., \& da Silva, A. J. R. (2017). Citrus species essential oils and their components can inhibit or stimulate fungal growth in fruit. Industrial Crops and Products, 98, 108-115. http://dx.doi.org/10.1016/j. indcrop.2017.01.026.

Simoncini, N., Virgili, R., Spadola, G., \& Battilani, P. (2014). Autochthonous yeasts as potential biocontrol agents in dry-cured meat products. Food Control, 46, 160-167. http://dx.doi.org/10.1016/j.foodcont.2014.04.030.

Soares, G. A. M., \& Sato, H. H. (2000). Characterization of the Saccharomyces cerevisiae Y500-4L killer toxin. Brazilian Journal of Microbiology, 31(4), 291-297. http:// dx.doi.org/10.1590/S1517-83822000000400010.

Solaimani, B., Ramezani, M., \& Saharkiz, M. J. (2009). Biological control of postharvest disease caused by Penicillium digitatum and P. italicum on stored citrus fruits by Shiraz thyme essential oil. Advances in Environmental Biology, 3, 249-254.

Somers, J. M., \& Bevan, E. A. (1969). The inheritance of the killer character in yeast. Genetical Research, 13, 71-83

Spadaro, D., \& Droby, S. (2016). Development of biocontrol products for postharvest diseases of fruit: The importance of elucidating the mechanisms of action of yeast antagonists. Trends in Food Science \& Technology, 47, 39-49. http://dx.doi.org/10.1016/j.tifs.2015.11.003.

Sperandio, E. M., Martins do Vale, H. M., \& Moreira, G. A. M. (2015). Yeasts from native Brazilian Cerrado plants: occurrence, diversity and use in the biocontrol of citrus green mould. Fungal Biology, 119(11), 984-993. http:// dx.doi.org/10.1016/j.funbio.2015.06.011. PMid:26466874.

Sun, C., Lin, M., Fu, D., Yang, J., Huang, Y., Zheng, X., $\&$ Yu, T. (2017). Yeast cell wall induces disease resistance against Penicillium expansum in pear fruit and the possible mechanisms involved. Food Chemistry, 241, 301-307. http://dx.doi.org/10.1016/j.foodchem.2017.08.092. PMid:28958532.

Sutherland, I. W. (1999). Polysaccharases for microbial exopolysaccharides. Carbohydrate Research, Amsterdam, 38, 319-328.

Talibi, I., Askarne, L., Boubaker, H., Boudyach, E. H., \& Aoumar, A. A. B. (2011). In vitro and in vivo antifungal activities of organic and inorganic salts against citrus sour rot agent Geotrichum candidum. Plant Pathology Journal, 10(4), 1-9.

Talibi, I., Boubaker, H., \& Boudyach, E. H. (2014). Métodos Ait Ben Aoumar A. Alternativas para o controle de doenças pós-colheita de citrinos. Journal of Applied Microbiology, 117(1), 1-17. http://dx.doi.org/10.1111/ jam.12495

Terao, D., de Lima Nechet, K., Ponte, M. S., de Holanda Nunes Maia, A., de Almeida Anjos, V. D., \& de Almeida Halfeld-Vieira, B. (2017). Physical postharvest treatments combined with antagonistic yeast on the control of orange green mold. Scientia Horticulturae, 224, 317-323. http:// dx.doi.org/10.1016/j.scienta.2017.06.038.

Torres, R., Usall, J., Plaza, P., Teixidó, N., Abadias, M., \& Vinãs, I. (2008). Alternativas al uso de fungicidas de síntesis para el control de podredumbres en cítricos. In L. M. Nascimento, J. D. De Negri, \& D. Mattos Junior (Ed.), Tópicos em qualidade e pós-colheita de frutas (Cap. 14, pp. 189-199). Campinas: Instituto Agronômico; FUNDAG.

Tripathi, P., Dubey, N. K., \& Shukla, A. K. (2008). Use of some essential oils as post-harvest botanical fungicides in the management of grey mould of grapes caused by Botrytis cinerea. World Journal of Microbiology \& Biotechnology, 24(1), 39-46. http://dx.doi.org/10.1007/ s11274-007-9435-2.

Turra, C., \& Santos, P. S. (2016). Characteristics of organic citriculture in Brazil. European Journal of Sustainable Development, 5(3), 113-118.

Turra, C., Vian, C. E. F., Nielsen, F. A. G., Santos, P. S., \& Penteado, L. F. F. (2014). Overview of the Brazilian citriculture certification. Journal of Agricultural and Environmental Ethics, 27(4), 663-679.

Ullivarri, M. F., Mendoza, L. M., \& Raya, R. R. (2018). Characterization of the killer toxin KTCf20 from Wickerhamomyces anomalus, a potential biocontrol agent 
against wine spoilage yeasts. Biological Control, 121, 223228. http://dx.doi.org/10.1016/j.biocontrol.2018.03.008.

United States Department of Agriculture - USDA. (2018). Citrus: world markets and trade. Recuperado em 2 de fevereiro de 2018, de https://public.govdelivery.com/ accounts/USDAFAS/subscriber/new

Valenzuela, N. L., Angel, D. N., Ortiz, D. T., Rosas, R. A., García, C. F. O., \& Santos, M. O. (2015). Biological Control of anthracnose by postharvest applicatin of Thichodema spp. on marodal papaya frut. Biological Control: Theory and Applications in Pest Management, 91, 88-93. http:// dx.doi.org/10.1016/j.biocontrol.2015.08.002.

Viana, S. S. M., \& Amorim, M. C. C. T. (2008). Caracterização do clima urbano em Teodoro Sampaio/ SP: uma introdução. Sociedade \& Natureza, 20(2), 19-42. http://dx.doi.org/10.1590/S1982-45132008000200002.

Volpe, C. A., Schöffel, E. R., \& Barbosa, J. C. (2002). Influência da soma térmica e da chuva durante o desenvolvimento de laranjas 'Valência' e 'Natal' na relação entre sólidos solúveis e acidez e no índice tecnológico do suco. Revista Brasileira de Fruticultura, 24(2), 436-441. http://dx.doi.org/10.1590/S0100-29452002000200031.

Vos, C. M. F., Cremer, K., Cammue, B. P. A., \& Coninck, B. (2015). The toolbox of Trichoderma spp. in biocontrol of Botrytis cinerea disease. Molecular Plant Pathology, 16(4), 400-412.

Wilson, C. L., \& Wisniewski, M. E. (1989). Biological control of postharvest diseases of expression following interaction with Penicillium digitatum and grapefruit peel. BMC Genomics, 14(1), 168.

Wilson, C. L., Wisniewski, M. E., Droby, S., \& Chalutz, E. (1993). A selection strategy for microbial antagonists to control postharvest diseases of fruits and vegetables.
Scientia Horticulturae, 53(3), 183-189. http://dx.doi. org/10.1016/0304-4238(93)90066-Y.

Wisniewski, M., Droby, S., Norelli, J., Liu, J., \& Schena, L. (2016). Alternative management technologies for postharvest disease control: the journey from simplicity to complexity. Postharvest Biology and Technology, 122, 3-10. http://dx.doi.org/10.1016/j.postharvbio.2016.05.012.

Xu, B., Zhang, H., Chen, K., Xu, Q., Yao, Y., \& Gao, H. (2013). Biocontrol of postharvest Rhizopus decay of peaches with Pichia caribbica. Current Microbiology, 67(2), 255-261. http://dx.doi.org/10.1007/s00284-0130359-9. PMid:23536217.

Yang, A., Liu, L., Li, D., Xia, S. U., Su, X., Peng, L., \& Pan, S. (2016). Use of active extracts of poplar buds against Penicillium italicum and possible modes of action Shuzhen. Food Chemistry, 196, 610-618. http://dx.doi. org/10.1016/j.foodchem.2015.09.101. PMid:26593534.

Yang, S., Zhou, J., Li, D., Shang, C., Peng, L., \& Pan, S. (2017). The structure-antifungal activity relationship of 5,7-dihydroxyflavonoids against Penicillium italicum. Food Chemistry, 224, 26-31. http://dx.doi.org/10.1016/j. foodchem.2016.12.001. PMid:28159264.

Zhu, C., Shi, J., Jiang, C., \& Liu, Y. (2015). Inhibition of the growth and ochratoxin A production by Aspergillus carbonarius and Aspergillus ochraceus in vitro and in vivo through antagonistic yeasts. Food Control, 50, 125-132. http://dx.doi.org/10.1016/j.foodcont.2014.08.042.

Recebido: Setembro 30, 2019

Aceito: Maio 07, 2020

Como citar: Rodrigues, P. L., Silva, J. L., Alfaia, J. P., Souza, J. C. \& Macedo, L. P. (2020). Potencial de biocontrole das leveduras em pós-colheita de citros pela produção da enzima $\beta$-1,3-glucanase e atividade killer: uma revisão. Citrus Research \& Technology, 41, e1056. https://doi.org/10.4322/crt.20020 